\title{
Analysis of cysteine-containing proteins using precolumn derivatization with $N$-(2-ferroceneethyl)maleimide and liquid chromatography/electrochemistry/mass spectrometry
}

\author{
Bettina Seiwert • Uwe Karst
}

Received: 16 January 2007 /Revised: 9 March 2007 / Accepted: 12 March 2007 / Published online: 17 April 2007

(C) Springer-Verlag 2007

\begin{abstract}
N$-(2-Ferroceneethyl)maleimide (FEM) is introduced as an electroactive derivatizing agent for thiol functionalities in proteins. Using appropriate reaction conditions, the derivatization is completed within five minutes and no unspecific labeling of free amino functions is observed. Liquid chromatography/electrochemistry/mass spectrometry was used to detect the reaction products. The reagent is a useful tool for determining the number of free thiol groups or the total number of free and disulfide-bound thiol groups in proteins. The electrochemical cell provides additional information, because the increase in mass spectrometric response upon electrochemical oxidation of the neutral ferrocene to the charged ferrocinium groups is monitored. The method was successfully applied to the analysis of native proteins and their tryptic digests.
\end{abstract}

Keywords Cysteine · Proteins · Derivatization · $\mathrm{N}$-(2-ferroceneethyl)maleimide $\cdot$ Liquid chromatography/ mass spectrometry Electrochemical conversion

Dedicated to Prof. Werner Engewald on the occasion of his 70th birthday.

B. Seiwert · U. Karst

Chemical Analysis Group and MESA+

Institute for Nanotechnology, University of Twente,

P.O. Box 217, 7500 AE Enschede, The Netherlands

Present address:

U. Karst $(\square)$

Institute of Inorganic and Analytical Chemistry,

University of Münster,

Corrensstr. 30,

48149 Münster, Germany

e-mail: uk@uni-muenster.de

\section{Introduction}

The on-line combination of electrochemistry and mass spectrometry has been used increasingly in recent years. The possibilities and limitations of using EC/MS to mimic phase 1 oxidative reactions in drug metabolism were studied by Jurva et al. [1] and compared to cytochrome P450-catalyzed oxidation reactions [2]. Furthermore, as an alternative to enzymatic protein digestion methods, the oxidation of tryptophan and tyrosin in proteins may give rise to peptide bond cleavage, as shown by Permentier et al. [3]. Using on-line oxidation, electroactive analytes may be converted into radical ions or products that yield better detection limits with mass spectrometric detection, as shown for example for PAHs [4] and phenothiazine [5] and its derivatives. For analytes without electroactive functionalities, the use of ferrocene-based reagents has been reported to increase the limits of detection. Van Berkel and co-workers [6] introduced ferrocenoyl azide for the analysis of alcohols in natural products. They used the electrolysis inherent in the electrospray instead of an external electrochemical cell and obtained impressive limits of detection. Diehl et al. [7, 8] used ferrocenoyl chloride for the determination of alcohols and phenols based on the on-line combination of liquid chromatography, electrochemistry and mass spectrometry. For this work, a commercial electrochemical cell, which can provide a quantitative conversion rate under optimum conditions, was used. The different approaches employed to combine electrochemistry and mass spectrometry are described in more detail in original papers by Van Berkel et al. [9] and in reviews by Diehl and Karst [10, 11]. Ferrocene-based derivatizing agents were used for other classes of compounds too. Semiquantitative analysis of catechol estrogens as their ferrocene boronate esters using ESI-MS with one- 
electron oxidation in the source using a nonaqueous solvent system (a mixture of dichloromethane and acetonitrile (ACN) with lithium triflate as the working electrolyte) was applied by Williams et al. [12]. $1 \alpha$-Hydroxyvitamin $\mathrm{D}_{3}$ in rat plasma was determined by ESI-MS after derivatization with 4-ferrocenylmethyl-1,2,4-triazoline-3,5-dione by Murao et al. [13]. At a low capillary voltage, the ferrocinium cation was produced. This was advantageous for selectivity because the ionization of most other compounds is inefficient at the conditions used. For the analysis of isocyanates in air samples by LC/EC/MS, ferrocenoyl piperazide proved to be useful as derivatizing agent [14].

Cysteine residues and disulfide bonds are important for protein structure and function. They stabilize the conformation of molecules through disulfide linkages during the process of protein folding [15]. The activities of some enzymes depend directly on the existence of free thiol functionalities, which participate in substrate binding and catalysis [16]. Therefore, the identification of thiol functionalities in proteins and peptides is necessary to understand these properties. Thiol-containing compounds are labile due to the high reactivity of the thiol group and are easily transformed into disulfides upon oxidation. Their analysis therefore requires immediate stabilization to preserve the original oxidation state [17]. In many cases, derivatization is used for stabilization purposes [15]. $N$-substituted maleimides are often used in protein chemistry for this purpose [18]. In those cases where combination with a reversed-phase separation is intended, reagents that lead to low-polarity products are advantageous. Therefore, ferroceneethylmaleimide (FEM) appears to be a promising reagent for this work. It was originally developed by Shimada et al. for the determination of thiols by HPLC with electrochemical detection [19, 20]. Later it was also used to introduce an IR probe [21], a redox-active reporter group [22], and an electroactive label into a nonelectroactive enzyme [23] in order to design new electrochemical biosensors. Furthermore, the attachment of maleimide-containing ferrocene derivatives onto selfassembled alkanethiol and alkanedithiol monolayers was studied [24]. However, the reagent has not yet been used in conjunction with liquid chromatography/mass spectrometry (LC/MS), although it appears to be particularly promising.

In this work, FEM is used for the first time as a reagent in the LC/MS analysis of thiol-containing proteins. Additional investigations focus on the possible use of an electrochemical cell in order to improve the limits of detection and to obtain important additional information on the products of the tryptic digest of the peptides.

\section{Experimental section}

Chemicals Tris-(2-carboxyethyl)-phosphine hydrochloride (TCEP), formic acid, ammonium hydrogencarbonate, ammonium formate, glutathione, all proteins and all fine chemicals were obtained from Sigma-Aldrich Chemie (Zwijndrecht, The Netherlands) at the highest purity available unless stated otherwise below. The solvents used for LC/MS were acetonitrile and water at LC/MS grade quality from Biosolve (Valkenswaard, The Netherlands). $\mathrm{N}$ (2-Ferroceneethyl)maleimide (FEM) was synthesized from ferrocenylmethyltrimethylammonium iodide (obtained from Alfa Aesar, Karlsruhe, Germany) according to a method described in the literature $[21,26,27]$ that was modified as indicated below.

Synthesis of FEM The synthetic route to FEM is shown in Fig. 1. It consists of the following three major steps:

A. Ferroceneacetonitrile (2) was synthesized from ferrocenylmethyltrimethylammonium iodide (1) according to Lednicer et al. [26]. Ferrocenylmethyltrimethylammonium iodide $(10 \mathrm{~g}, 26 \mathrm{mmol})$ and $10 \mathrm{~g}(153 \mathrm{mmol})$ potassium cyanide were dissolved in $100 \mathrm{~mL}$ water and the solution was heated under reflux. After two hours, the reaction mixture was cooled and extracted twice with $50 \mathrm{~mL}$ diethyl ether, washed twice with $20 \mathrm{~mL}$ water and dried over magnesium sulfate. The solvent was evaporated to yield $5.12 \mathrm{~g}(85 \%)$ of a yellow substance that was used for further reactions without further purification. ${ }^{1} \mathrm{H}-\mathrm{NMR}(300 \mathrm{MHz}$, $\left.\mathrm{CDCl}_{3}, \mathrm{TMS}\right) \delta(\mathrm{ppm}) 3.4(\mathrm{~s}, 2 \mathrm{H}), 4.1(\mathrm{~s}, 4 \mathrm{H}), 4.15$ (s, 5H).

B. 2-Ferroceneethylamine (3) was synthesized from ferrocenylacetonitrile by reduction with $\mathrm{LiAlH}_{4}$ as described in the literature [27]. However, some modifications were performed to improve the yield and reproducibility of the reaction. According to the literature, small portions of in total $1 \mathrm{~g}(26 \mathrm{mmol})$ $\mathrm{LiAlH}_{4}$ and $2.4 \mathrm{~g}(18 \mathrm{mmol})$ of $\mathrm{AlCl}_{3}$ were dissolved in $40 \mathrm{~mL}$ dry THF while stirring in an ice bath. Two grams $(9 \mathrm{mmol})$ of ferroceneacetonitrile dissolved in $20 \mathrm{~mL}$ THF were added and the mixture was refluxed for two hours. After cooling, water was carefully added dropwise to decompose the excess of $\mathrm{LiAlH}_{4}$. The green complex formed by $\mathrm{AlCl}_{3}$ and 2-ferroceneethylamine [28] had to be destroyed by adding $0.5 \mathrm{~mL}$ of concentrated $\mathrm{NaOH}$. The solution turned yellow, and the aqueous solution was extracted with diethyl ether three times. The combined organic extracts were dried over $\mathrm{MgSO}_{4}$ and evaporated to dryness. The purity of the red oily substance $(1.1 \mathrm{~g} / 54 \%)$ was investigated by 
Fig. 1 Scheme used to synthesize FEM

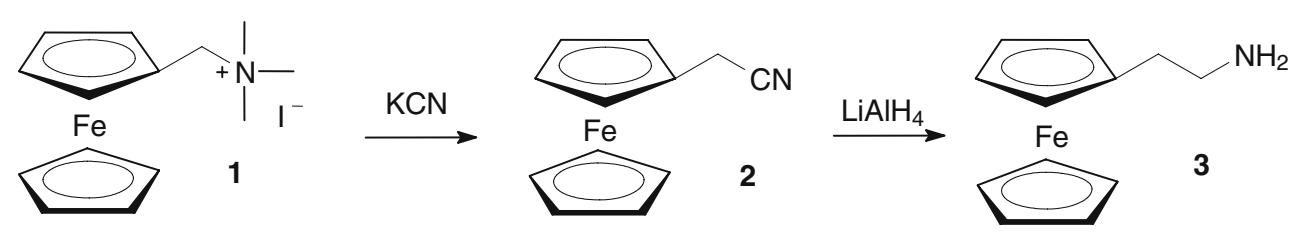

a
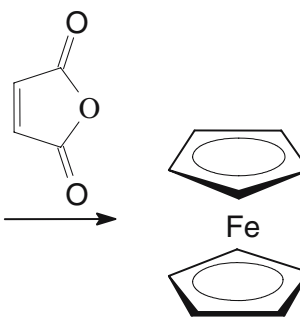

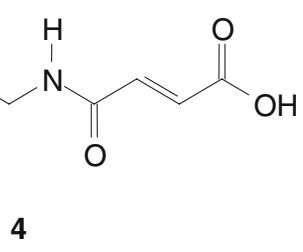

b

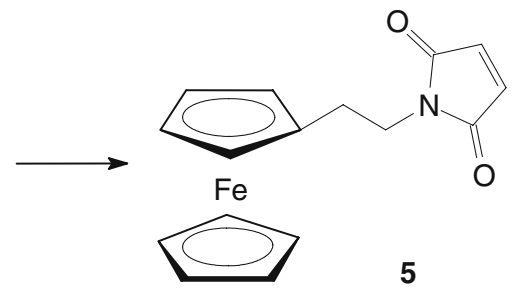

C

ESI-MS: $m / z=230[\mathrm{M}+\mathrm{H}]^{+}, \mathrm{MS} / \mathrm{MS}: m / z=213,{ }^{1} \mathrm{H}-$ NMR (300 MHz, $\left.\mathrm{CDCl}_{3}, \mathrm{TMS}\right) \delta(\mathrm{ppm}) 2.48(\mathrm{t}, 2 \mathrm{H})$, 2.81(t, 2H), $4.00(\mathrm{~s}, 4 \mathrm{H}), 4.05(\mathrm{~s}, 5 \mathrm{H})$.

C. 2-Ferroceneethylamine ( $460 \mathrm{mg}, 2 \mathrm{mmol})$, the product obtained from B, was dissolved in dry THF $(20 \mathrm{~mL})$ and mixed with $220 \mathrm{mg}(2.4 \mathrm{mmol})$ maleic anhydride, which was also dissolved in dry THF $(10 \mathrm{~mL})$. After stirring the reaction mixture for one hour in an ice bath, the solvent was removed by evaporation and the crude $N$-(2-ferroceneethyl)maleic acid (4) obtained was, in contrast to the approach described in the literature [12], purified by column liquid chromatography using silica gel with ethyl acetate/chloroform (9:1) as the mobile phase. ESI-MS: $m / z=327[\mathrm{M}+\mathrm{H}]^{+}$. The product (400 mg, $1.2 \mathrm{mmol}$ ) was added to a solution of $4 \mathrm{~mL}$ acetic anhydride and $0.6 \mathrm{~g}$ ammonium acetate and heated for $10 \mathrm{~min}$ to $100^{\circ} \mathrm{C}$. Afterwards, $30 \mathrm{~mL}$ water and $20 \mathrm{~mL}$ ethyl acetate were added and the aqueous phase was extracted with ethyl acetate three times. The combined organic phases were washed with $\mathrm{NaHCO}_{3}$ and brine, dried over $\mathrm{MgSO}_{4}$, and evaporated to dryness. Column liquid chromatography was performed on silica gel using chloroform/ethyl acetate $(2: 1)$ as the mobile phase and $209 \mathrm{mg}(56 \%) \mathrm{N}$-(2ferroceneethyl)maleimide (5) was obtained. ESI-MS: $m / z=309[\mathrm{M}+\mathrm{H}]^{+},{ }^{1} \mathrm{H}-\mathrm{NMR}\left(300 \mathrm{MHz}, \mathrm{CDCl}_{3}, \mathrm{TMS}\right)$ $\delta(\mathrm{ppm}) 2.56(\mathrm{t}, 2 \mathrm{H}), 3.65(\mathrm{t}, 2 \mathrm{H}), 4.10(\mathrm{~s}, 4 \mathrm{H}), 4.15$ (s, 5H), $6.68(\mathrm{~s}, 2 \mathrm{H})$.

Derivatization of proteins Stock solutions were prepared of the following compounds: FEM $(20 \mathrm{mM})$ in $\mathrm{ACN}$, urea $(8 \mathrm{M})$ in $\mathrm{NH}_{4}$ ac buffer $\left(100 \mathrm{mM}, \mathrm{pH}\right.$ 6.8) or $\mathrm{NH}_{4} \mathrm{HCO}_{3}$ buffer (100 mM, pH 7.8) and TCEP $(100 \mathrm{mM})$ in $0.3 \mathrm{M}$ aqueous ammonia solution. The proteins of interest were dissolved and denatured in urea to form a $0.125 \mathrm{mM}$ solution. The derivatization was carried out using a tenfold molar excess of FEM with respect to the thiol groups in the proteins. Reduction of disulfide bonds was performed with a ninefold molar excess of TCEP with respect to the thiol groups for $30 \mathrm{~min}$ before derivatization. Afterwards, formic acid was added to decrease the $\mathrm{pH}$ value to acidic conditions. As an example, the derivatization of $\beta$-lactoglobulin $A$ is now described. For the derivatization of free cysteine groups, $65 \mu \mathrm{L}$ of $20 \mathrm{mM}$ FEM solution was added to $1 \mathrm{~mL}$ of $\beta$ lactoglobulin $\mathrm{A}$ (dissolved in $\mathrm{NH}_{4} \mathrm{ac}-$-urea, see above). To derivatize the disulfide-bound cysteines too, first $60 \mu \mathrm{L}$ of TCEP were added to the protein solution (preferably in urea$\mathrm{NH}_{4} \mathrm{HCO}_{3}$ ) and then $320 \mu \mathrm{L}$ of the FEM solution were added. Finally, the protein solutions exceeding $3 \mathrm{kDa}$ were passed through a PD-10 desalting column (Amersham Bioscience, Freiburg, Germany) to remove the excess reagent and reduction agent. Therefore, $0.01 \%$ formic acid was used as mobile phase.

Digestion with trypsin A stock solution of trypsin $(1 \mu \mathrm{g} / \mathrm{mL}$ in $0.01 \%$ formic acid, diluted 1:10 immediately before use in $100 \mathrm{mM} \mathrm{NH}_{4} \mathrm{HCO}_{3}$ ) was prepared first. For the in-solution digest, $150 \mu \mathrm{L}$ trypsin solution were added to $200 \mu \mathrm{L}$ of the desalted protein ( $\beta$-lactoglobulin A) solution containing approximately $0.03 \mathrm{mM}$ protein in $0.01 \%$ formic acid (trypsin:protein ratio of $1: 20(\mathrm{w} / \mathrm{w})$ ), and the mixture was incubated overnight at $37^{\circ} \mathrm{C}$.

Analysis of the derivatized proteins A LC/MS system from Agilent Technologies (Amstelveen, The Netherlands), which consisted of a G1322 vacuum degasser, a G1316 thermostated column compartment, a G1367 well plate sampler, a G1311 quarternary pump and a G1956B LC/ MSD SL single-quadrupole mass spectrometer was used. 
Table 1 The gradient profiles selected for the measurements

\begin{tabular}{|c|c|c|c|c|c|c|c|c|}
\hline \multicolumn{9}{|c|}{ Gradient profiles } \\
\hline \multicolumn{9}{|l|}{ A } \\
\hline$t[\mathrm{~min}]$ & 0 & 1 & 20 & 22 & 23 & 25 & & \\
\hline$c(\mathrm{ACN})[\%]$ & 10 & 10 & 100 & 100 & 10 & Stop & & \\
\hline \multicolumn{9}{|l|}{ B } \\
\hline$t[\mathrm{~min}]$ & 0 & 1 & 25 & 27 & 29 & 32 & & \\
\hline$c(\mathrm{ACN})[\%]$ & 10 & 10 & 100 & 100 & 10 & stop & & \\
\hline \multicolumn{9}{|l|}{$\mathrm{C}$} \\
\hline$t[\mathrm{~min}]$ & 0 & 1 & 5 & 20 & 22 & 24 & 25 & 30 \\
\hline$c(\mathrm{ACN})[\%]$ & 5 & 5 & 60 & 75 & 100 & 100 & 5 & stop \\
\hline
\end{tabular}

The column employed for the MS measurements was a Discovery BioWidePore C5-5 column (Supelco, Taufkirchen, Germany) with a particle size of $5 \mu \mathrm{m}$, a length of $150 \mathrm{~mm}$ and an inner diameter of $2.1 \mathrm{~mm}$. The injection volume was $10 \mu \mathrm{L}$. A flow rate of $0.3 \mathrm{~mL} / \mathrm{min}$ was selected. Table 1 shows the three gradient profiles selected for the measurements.

A binary gradient of a) $0.1 \%$ formic acid in water $/ 0.1 \%$ formic acid in acetonitrile, and b) $10 \mathrm{mM} \mathrm{NH}_{4} \mathrm{HCO}_{3}$ buffer and acetonitrile was employed. Scan data were recorded from $\mathrm{m} / \mathrm{z} 130$ to $\mathrm{m} / \mathrm{z} 2000$ with the following parameters: fragmentor 70 , gain of 1 , threshold of 150 , and a step size of 0.1. For data analysis and deconvolution, Chemstation Rev. A.10.02 software (Agilent) was used.

Conditions for cyclic voltammograms The FEM derivative of glutathione was prepared by mixing equimolar amounts of glutathione in $10 \mathrm{~mL} \mathrm{NH} \mathrm{NCO}_{3}$ buffer $(100 \mathrm{mM}$, pH 7.8) and the FEM was dissolved in $10 \mathrm{~mL}$ acetonitrile to form a $0.1 \mathrm{mM}$ solution of glutathione derivative. After $5 \mathrm{~min}$ of stirring under a nitrogen atmosphere, the stirrer was turned off and cyclic voltammograms were recorded over the potential range -500 to $1000 \mathrm{mV}$ at a scan rate of $50 \mathrm{mV} / \mathrm{s}$.

LC/EC/MS analysis To hyphenate the LC/MS system with on-line electrochemistry, a conditioning cell model 5021 and a Coulochem II potentiostat from ESA Bioscience Inc. (Chelmsford, MA, USA) was inserted between the outlet of the UV/vis detector and the inlet of the ionization interface of the mass spectrometer. To protect the working electrode, a PEEK in-line filter (ESA) was mounted between the column and electrode. It should be noted that all potentials provided for the ESA cell were measured vs. a $\mathrm{Pd} / \mathrm{H}_{2}$ reference electrode, while the $\mathrm{CV}$ measurements were measured against $\mathrm{Ag} / \mathrm{AgCl}$, as indicated below.

\section{Results and discussion}

In this paper, we present a general strategy for identifying free and disulfide-bound cysteine (Cys) residues in proteins. $N$-(2-Ferroceneethyl)maleimide is used as a derivatizing agent. $N$-Substituted maleimides contain an activated double bond that can undergo a Michael-type electrophilic addition reaction by forming a stable thioether bond with sulfhydryl groups, as shown in Fig. 2 for Cys. Thiols preferentially react with maleimide groups by means of the thiolate anion. The reaction is fast and highly selective (at $\mathrm{pH} \mathrm{7,} \mathrm{the} \mathrm{maleimide} \mathrm{group} \mathrm{is} 1000$ times more reactive towards a sulfhydryl group than towards an amine), but it is strongly influenced by $\mathrm{pH}$ and temperature $[25,29]$. The reaction progress was investigated for glutathione, a tripeptide containing one Cys residue, using flow injection analysis (FIA) with MS detection of the derivative formed. At the conditions used $\left(10 \mathrm{mM} \mathrm{NH}_{4} \mathrm{HCO}_{3} \mathrm{pH} 7.8\right.$, room temperature, and tenfold molar reagent excess with respect to glutathione), the reaction was completed in less than $3 \mathrm{~min}$.

Three small proteins were selected for the investigation. Two of these are acidic (insulin with a pI of 5.3, and $\beta$-lactoglobulin A with a pI of 5.2) and one is basic (lysozyme with a pI of 11.35) [30-32]. Lysozyme contains eight Cys residues within four disulfide bridges [33]. Insulin consists of two chains (A and B) and possesses two intermolecular disulfide bridges and one intramolecular disulfide bridge [34]. $\beta$-Lactoglobulin A contains two disulfide bridges and one free cysteine [35]. TCEP was used as a reducing agent. TCEP is more stable than other reducing agents such as dithiothreitol (DTT) and $\beta$ mercaptoethanol, and it has the advantages of being water-soluble and nonvolatile. Furthermore, it exhibits a faster reaction [36]. Therefore, only half of the concentration of TCEP is typically applied compared with DTT under the same conditions [37]. Furthermore, TCEP possesses no thiol function, which could compete with the analyte for the derivatizing agent. However, it is known from the literature that using high concentrations of TCEP inhibits the labeling of proteins. There is an optimal ratio of

Fig. 2 Derivatization of cysteine with FEM

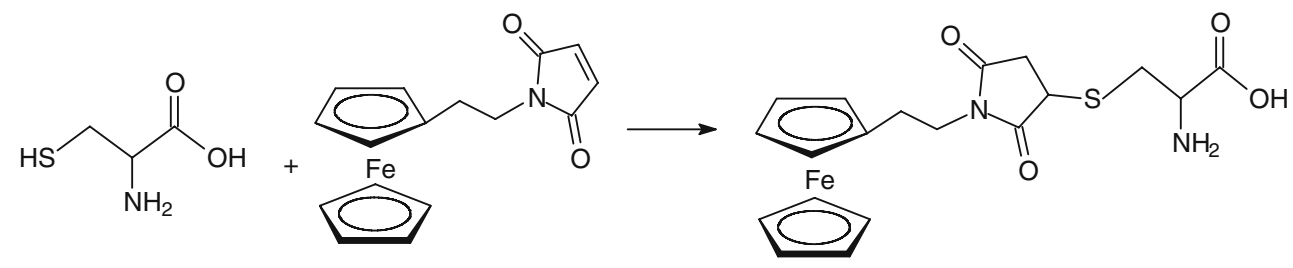


Fig. 3 TIC chromatogram and mass spectrum for lysozyme, which was denatured, reduced and derivatized with FEM after cleaning on a PD column (a); solvent a and gradient A were used. For comparison, the mass spectrum of lysozyme that was denatured and derivatized with FEM is shown as well (b)
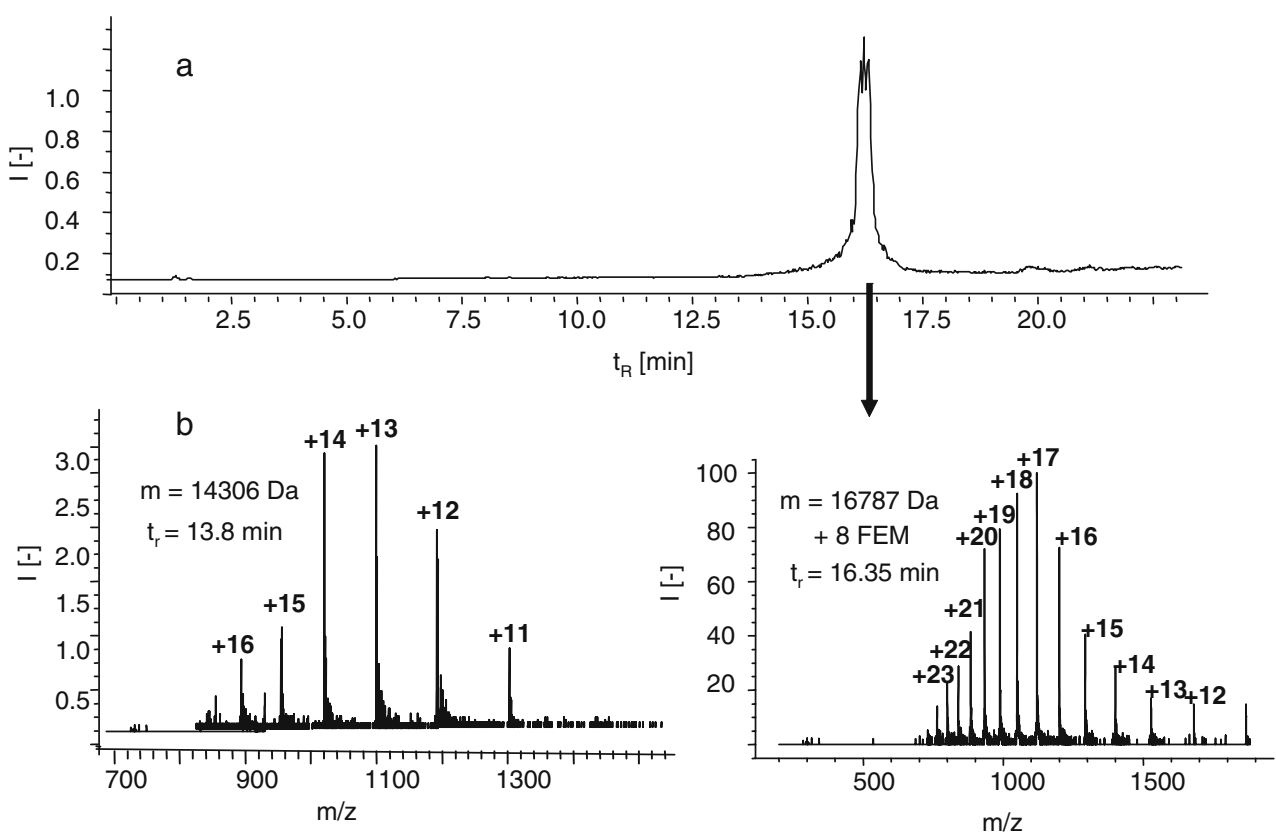

9:1 of TCEP over thiol and 10:1 of derivatizing agent over thiol [38]. In preliminary investigations, these ratios were proved to be applicable to thiol analysis with FEM as well. To investigate the progress of the reaction, a solution containing a protein denaturized with $8 \mathrm{M}$ urea was treated first with TCEP as reducing agent and then with FEM. Only one peak could be detected in the TIC chromatogram for derivatized lysozyme (Fig. 3a). Deconvolution of the mass spectrum shows that only the species with a mass of $16787 \mathrm{Da}$, the corresponding sodium adduct (16807 Da), and the potassium adduct (16826 Da) are present. For comparison, a spectrum of unreduced derivatized protein and deconvolution resulted in masses of $14306 \mathrm{Da}$ and $14328 \mathrm{Da}$ (sodium adduct) after deconvolution, as shown in Fig. 3b. The increase of $2481 \mathrm{Da}$ is due to the addition of eight FEM $(8 \times 309 \mathrm{Da}=2472 \mathrm{Da})$ molecules, which implies complete alkylation of the eight Cys residues and no additional involvement of the six Lys residues. The difference of $9 \mathrm{Da}$ between the measured and calculated data is due to the low mass accuracy of the single quadrupole mass spectrometer.

The TIC chromatogram of unreduced and derivatized insulin is shown in Fig. 4. A peak is present due to the excess of the derivatizing agent FEM, because the solution
Fig. 4 TIC chromatogram of insulin, which was denatured and treated with FEM with the corresponding mass spectra. Conditions: solvent a and gradient $\mathrm{A}$

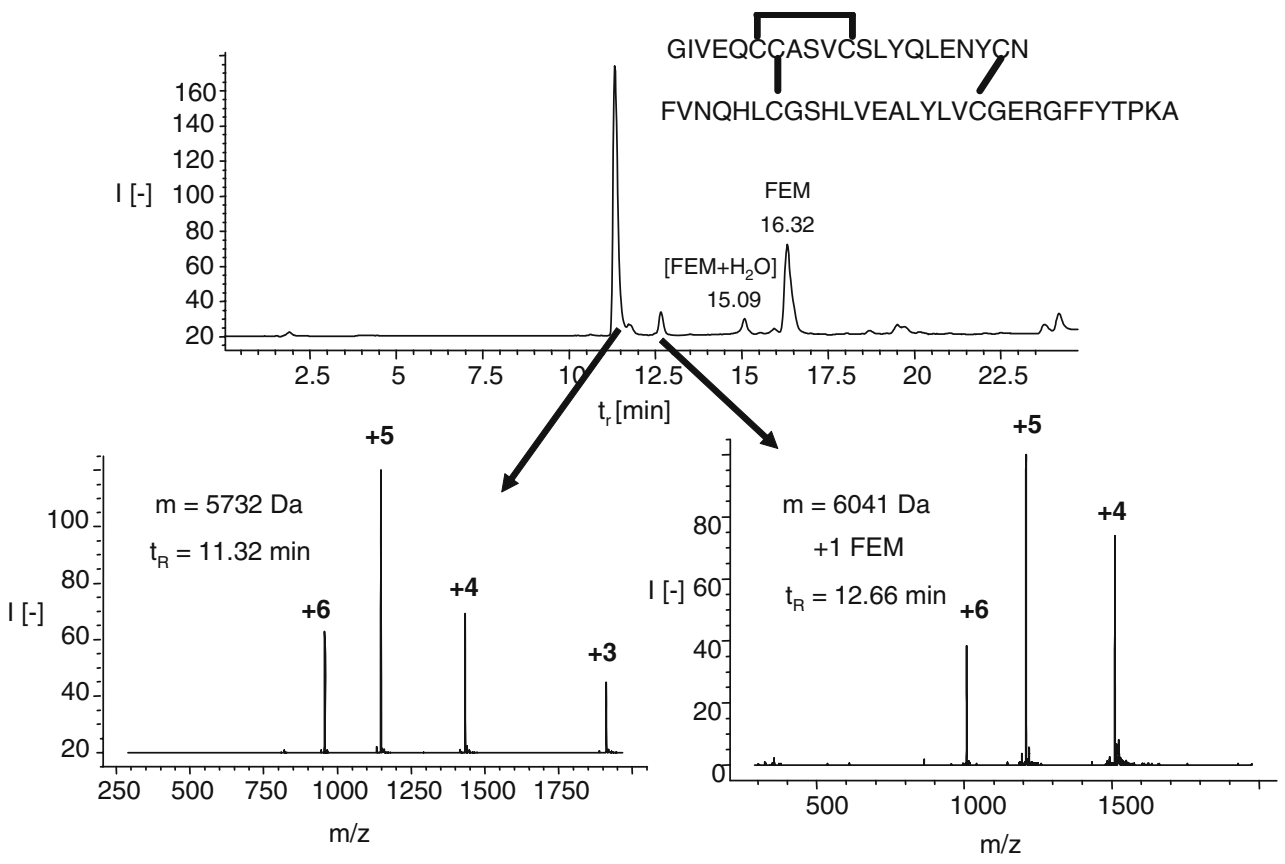


Fig. 5 LC/MS (a) and LC/EC/ MS (b) chromatograms for insulin, reduced and derivatized, along with the corresponding mass spectra of the A-chain and the B-chain. Conditions: solvent $\mathrm{b}$ and gradient $\mathrm{A}$

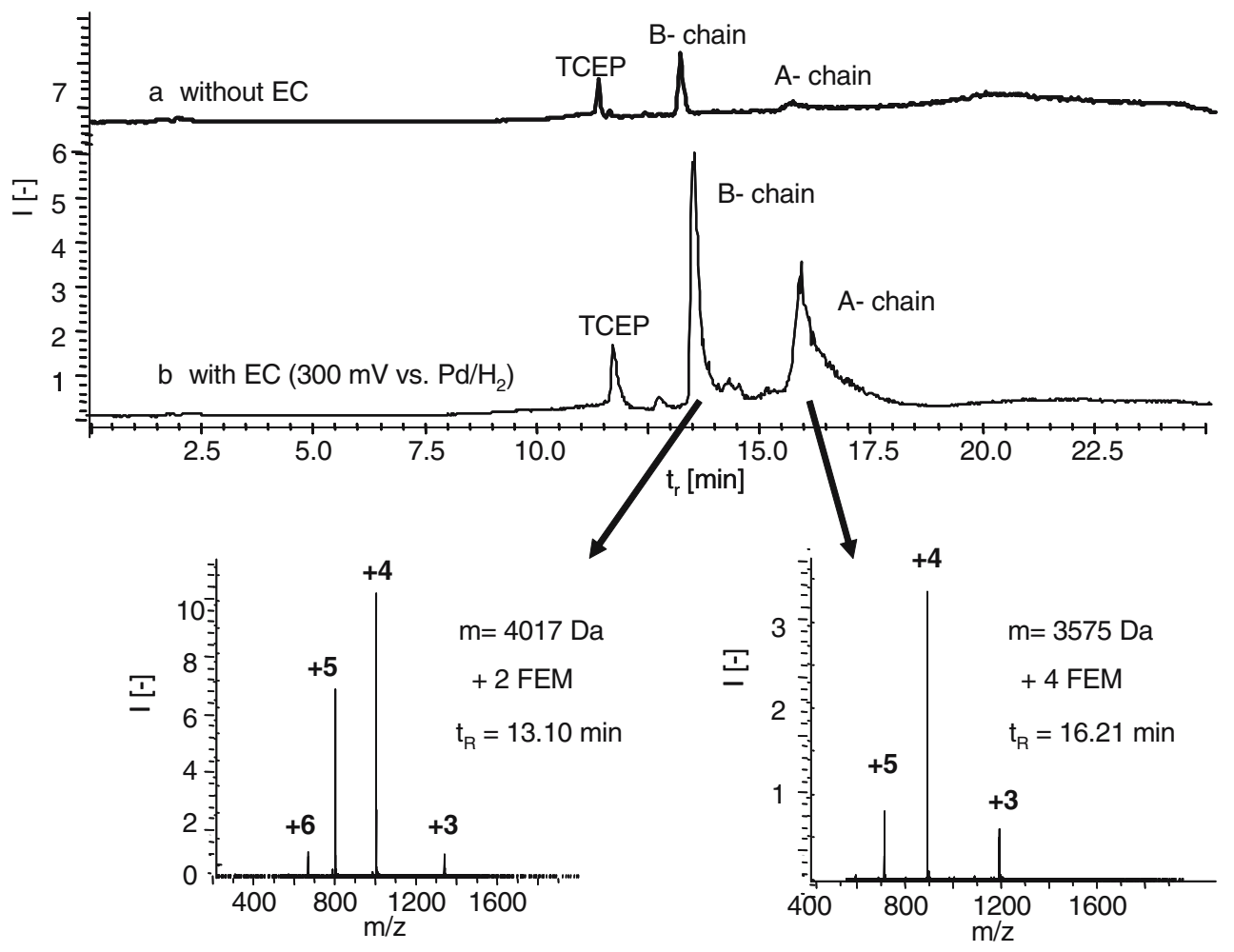

was not cleaned by a PD column in this case. A small peak appears at $t_{\mathrm{r}}=12.66 \mathrm{~min}$ with a deconvoluted mass of $6041 \mathrm{Da}$ as well as the main peak at $t_{\mathrm{r}}=11.32 \mathrm{~min}$ with a mass of $5732 \mathrm{Da}$. The difference of $309 \mathrm{Da}$ can be traced back to the addition of one FEM molecule, and it is a nonspecific adduct (probably with one Lys residue in the Bchain) because no free Cys residue is present in insulin. This happened only when $\mathrm{NH}_{4} \mathrm{HCO}_{3}$ buffer $(\mathrm{pH}$ 7.8) was used. The peak from the nonspecific adduct does not appear when $\mathrm{NH}_{4} \mathrm{ac}$ ( $\mathrm{pH}$ 6.8) is used to dissolve the protein (data not shown). For this reason, $\mathrm{NH}_{4}$ ac was used as the buffer in all subsequent labelling experiments. No further experiments were performed to study the labelling of lysine in proteins with FEM at a higher $\mathrm{pH}$. If insulin is reduced, two peaks appear in the chromatogram because the two chains of insulin are not connected (Fig. 5a). The increase in mass is equivalent to two FEM in the B-chain and four FEM in the A-chain. In the A-chain, two of the cysteins are directly adjacent, but they are labelled, too. Therefore, it can be concluded that no spatial discrimination of the derivatization reaction with the ferrocene label takes place under these conditions.

With FEM, an electroactive label is introduced into the proteins. To study the electrochemical behaviour and to obtain information about the half-wave potential of FEM derivatives, cyclic voltammetry was performed for deriva-
Fig. 6 Mass spectra for the A- and B-chains of insulin, reduced, derivatized and measured with LC/MS without EC

\section{A-chain}

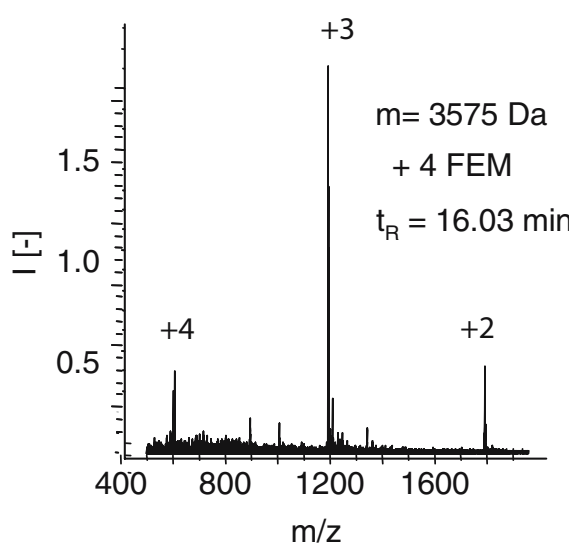

B-chain

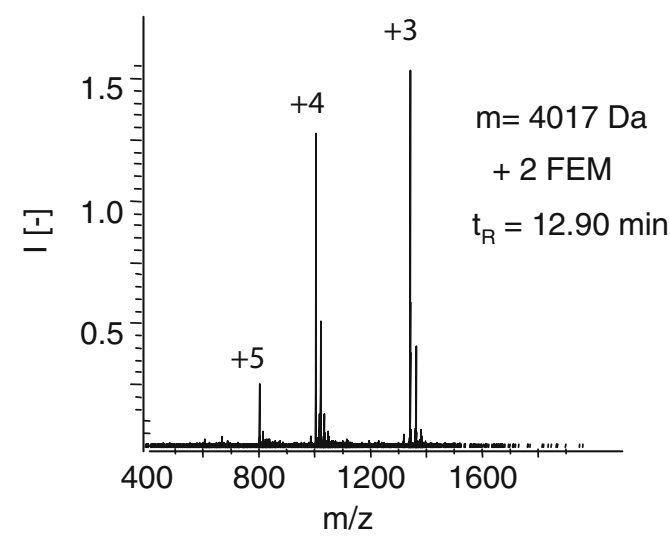


Fig. 7 LC/MS chromatogram of $\beta$-lactoglobulin A treated with FEM, along with the corresponding mass spectra and deconvolution data. Solvent system $b$ and gradient $B$ were used
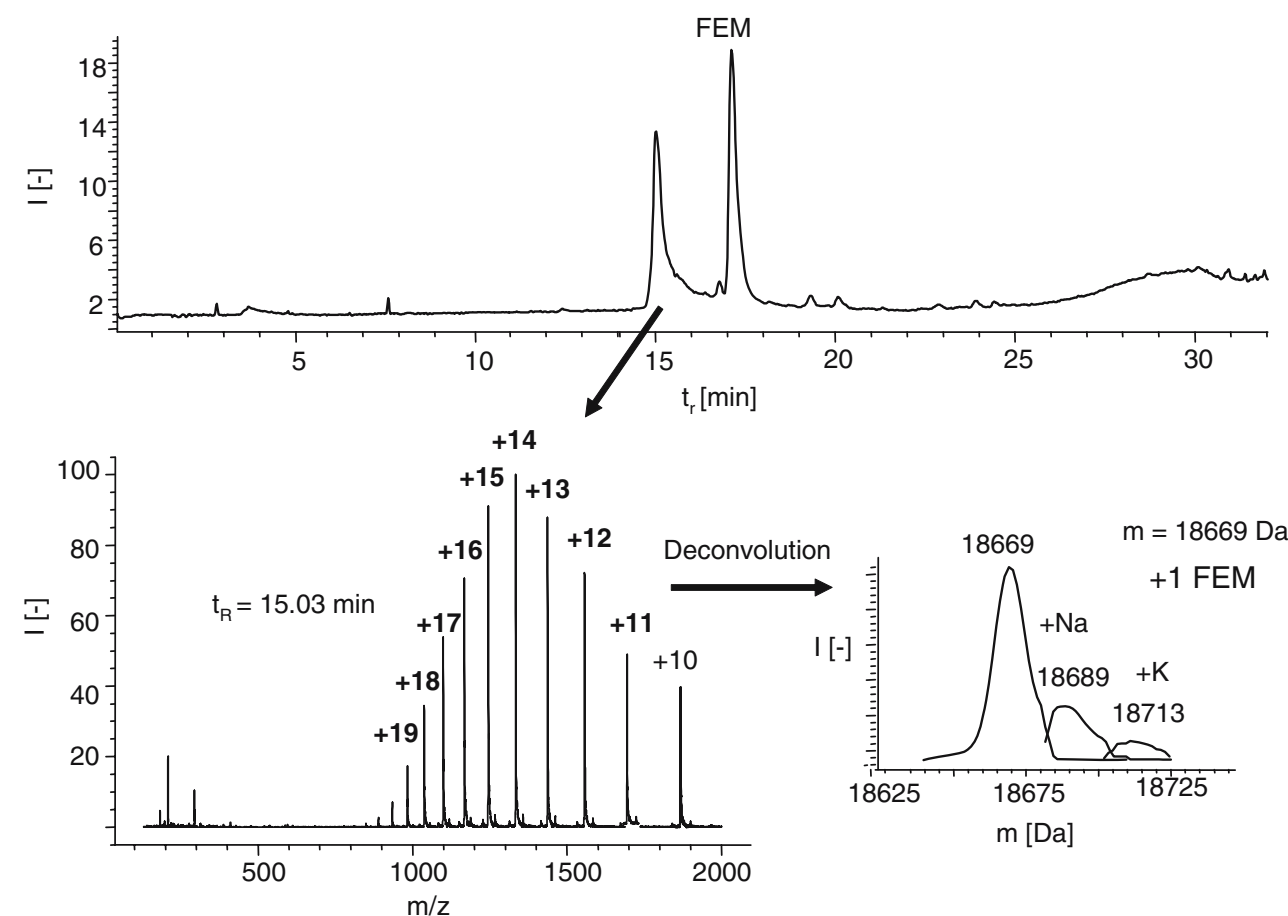

tized glutathione since it is a small and therefore easy to study example. The redox system shows a reversible oneelectron oxidation of the ferrocene derivative to the ferrocinium cation, and the half-wave potential is found to be $300 \mathrm{mV}$ vs. $\mathrm{Ag} / \mathrm{AgCl}$. For EC/MS measurements, an electrochemical flow cell containing a porous glassy carbon working electrode with a very large surface area was used to obtain a high conversion rate for the ferrocene derivatives. It was possible to increase the intensity and the average charge state of the protein by EC/ESI-MS detection. However, it is not possible to draw conclusions from the increase in charge the number of Cys residues. For the A chain and the B chain, the increase is equivalent to only one charge (Fig. 6). This is not surprising, because the proteins are already highly charged. Peak tailing was observed for the peaks corresponding to the A- and
Fig. $8 \mathrm{LC} / \mathrm{MS}$ chromatogram of $\beta$-lactoglobulin A. Disulfide bonds were reduced with TCEP and treated with FEM. The corresponding mass spectra and deconvolution data are also shown. Solvent system $b$ and gradient $\mathrm{C}$ were used
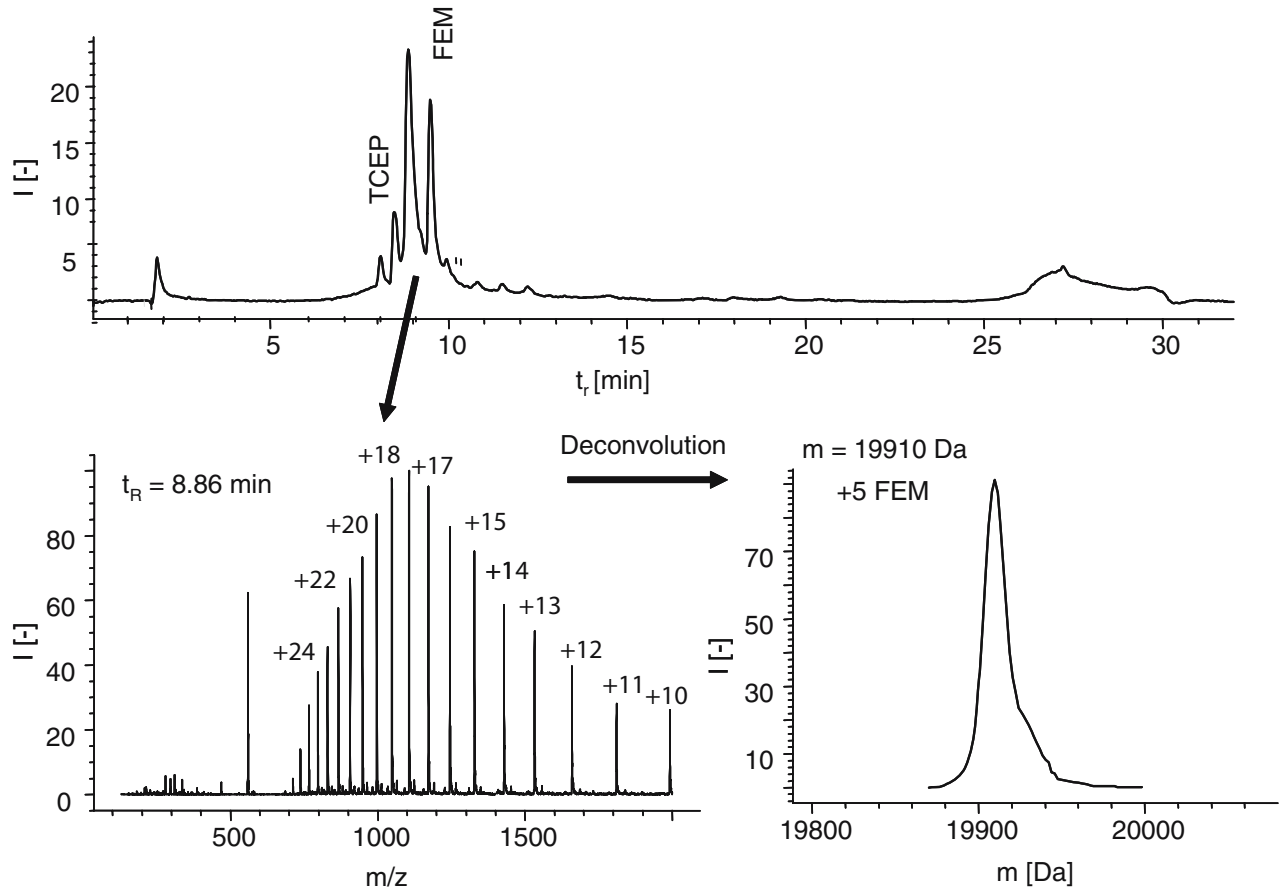
Fig. 9 TIC chromatogram of the trypsin digest of $\beta$-lactoglobulin A obtained with LC/ $\mathrm{EC} / \mathrm{MS}$ at a potential of $300 \mathrm{mV}$ (a) and LC/MS (b); LC conditions: gradient $\mathrm{A}$, solvent $\mathrm{a}$. The peak intensities of the peaks $\mathrm{A}$, $\mathrm{B}$ and $\mathrm{C}$ are enhanced in TIC trace a compared to $\mathbf{b}$
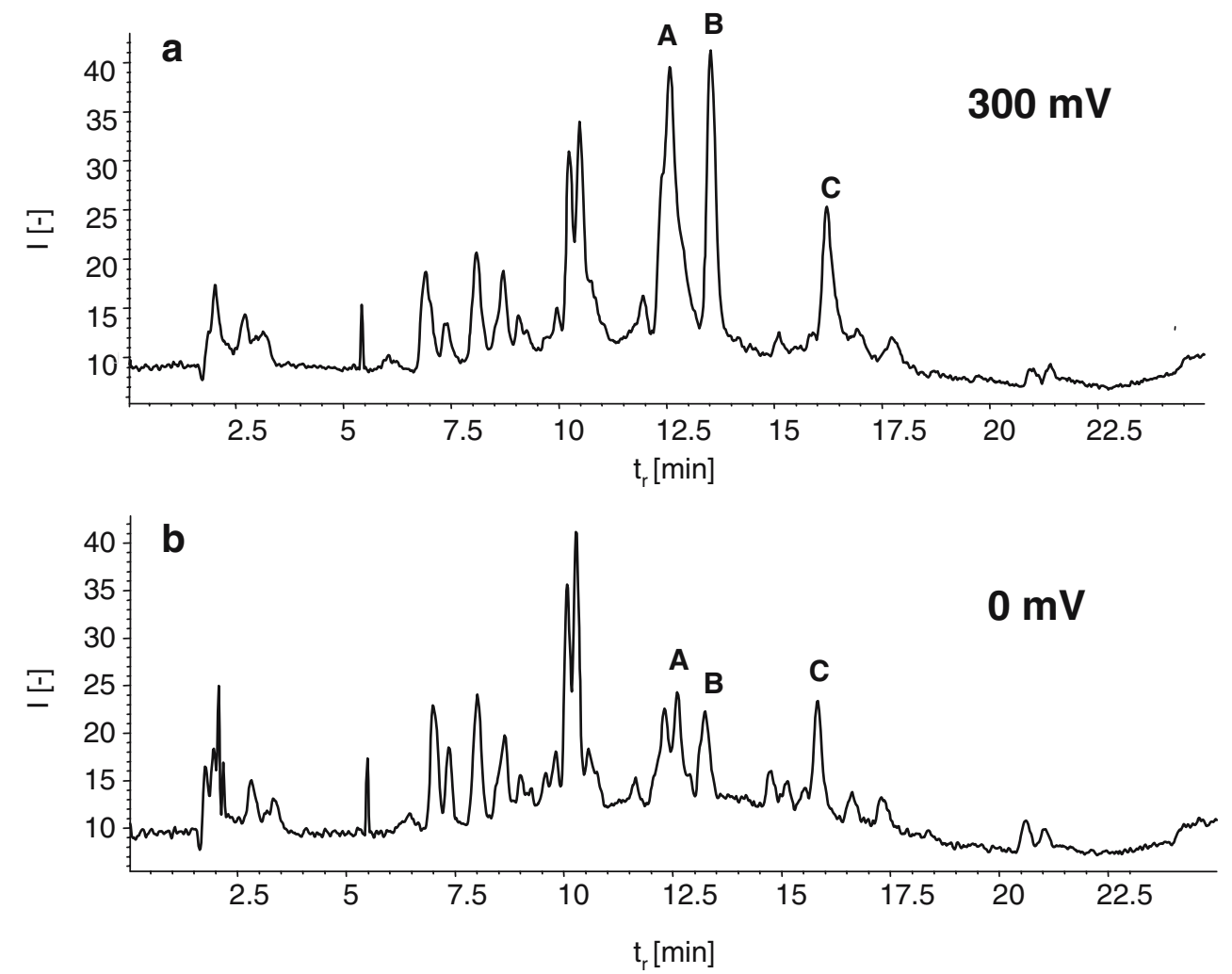

B-chain, probably due to adsorption to the glassy carbon working electrode of the electrochemical cell (Fig. 5b). However, the reproducibility of the LC separation was not affected.

$\beta$-Lactoglobin A possesses one free cysteine, as confirmed by the increase of $309 \mathrm{Da}$ to $18669 \mathrm{Da}$ (Fig. 7). There are only two peaks in the chromatogram (solvent system $b$ and gradient $B$ were used). One of these corresponds to the excess of the derivatizing reagent FEM $\left(t_{\mathrm{r}}=17.02 \mathrm{~min}\right)$, and the other one to the derivatized protein $\left(t_{\mathrm{r}}=15.03 \mathrm{~min}\right)$. No unlabelled protein $(18360 \mathrm{Da})$, which should elute at $t_{\mathrm{r}}=13.8 \mathrm{~min}$, could be detected. After reducing with TCEP, the TIC chromatogram became more complex (Fig. 8) due to the added reducing agent (recorded by using solvent system $\mathrm{b}$ and gradient $\mathrm{C}$ ). The signals at $t_{\mathrm{r}}=$ $8.1 \mathrm{~min}$ (dominant peak $\mathrm{m} / \mathrm{z}=578$ ) and $t_{\mathrm{r}}=8.5 \mathrm{~min}$ (dominant peak $m / z=560$ ) are caused by TCEP-FEM and the ferroceneethylsuccinamic acid derivative of TCEP, which is formed by the hydrolytic cleavage of the $\mathrm{N}-\mathrm{C}$ bond of the succinimide ring of FEM. The peak at $t_{\mathrm{r}}=9.5 \mathrm{~min}$ could be
Fig. 10 Mass spectra, compositions and masses of tryptic digest peptides containing derivatized thiol functionalities observed in the chromatogram shown in Fig. 9
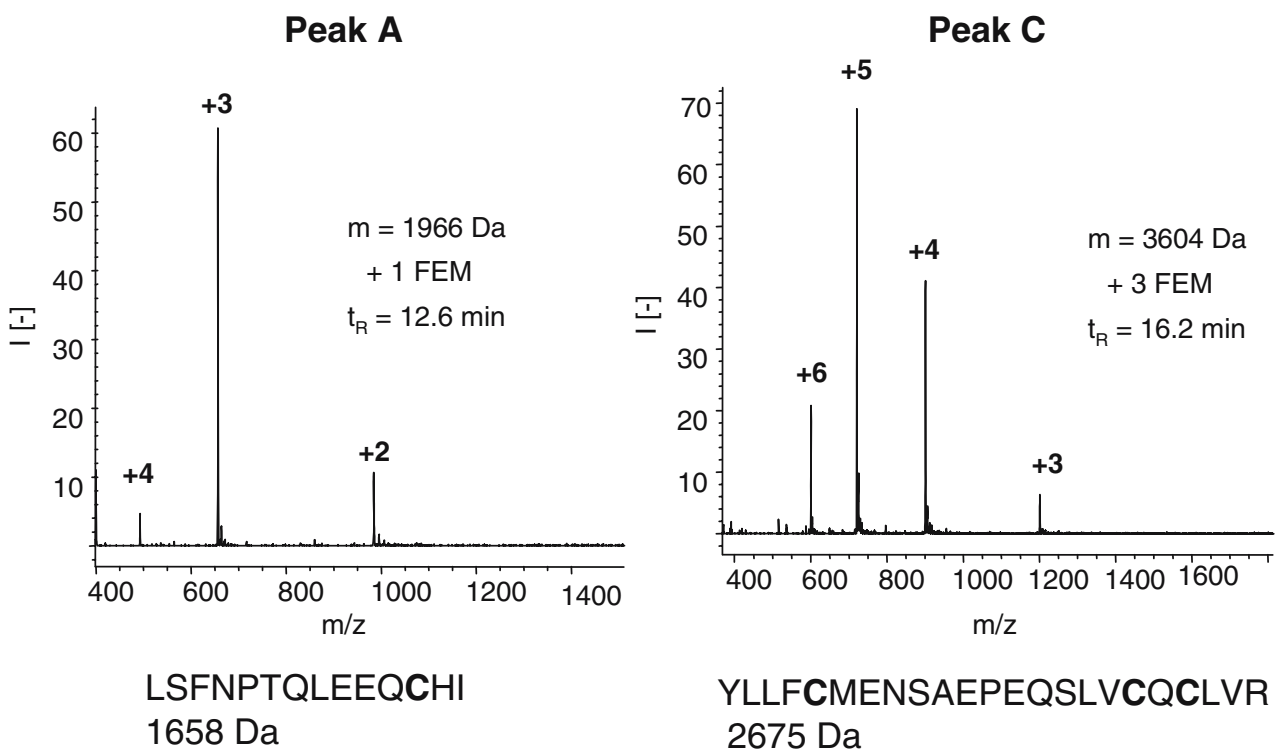

YLLFCMENSAEPEQSLVCQCLVR $2675 \mathrm{Da}$ 
attributed to the excess of derivatizing agent. Deconvolution of the mass spectrum of the peak at $t_{\mathrm{r}}=8.7 \mathrm{~min}$ leads to a mass of $19910 \mathrm{Da}$. This corresponds to an increase of $1550 \mathrm{Da}$, which is equivalent to the addition of five FEM (calculated: $1545 \mathrm{Da}$ ). Again, the differences can be attributed to the low mass accuracy of the mass analyzer used.

To obtain information about the position of the Cys residues in the proteins, a tryptic digest was performed. Trypsin cleaves proteins at the $\mathrm{C}$-terminal sides of lysine and arginine amino acid residues. The tryptic digest of the reduced and derivatized $\beta$-lactoglobulin A yields the TIC chromatogram shown in Fig. 9. By using electrochemistry/MS, an increase in the intensities of the peaks corresponding to peptides that contain one or more ferrocene units compared with those from the nonderivatized peptides could be detected. The increase was greatest at an optimum potential of $300 \mathrm{mV}$ vs. $\mathrm{Pd} / \mathrm{H}_{2}$, which confirms the earlier $\mathrm{CV}$ measurements. A further increase of the potential results in the same or less intensity. This may be explained by the behaviour of the model peptide glutathione. If glutathione is analysed by ESI-MS, the main peak corresponds to the protonated molecular ion $[\mathrm{M}+\mathrm{H}]^{+}$. Furthermore, there is an enhanced molecular ion peak $[\mathrm{M}]^{+}$. By switching on the electrochemical cell, which is inserted between the outlet of the LC column and the inlet of the mass spectrometer (EC/ESI-MS) at $300 \mathrm{mV}$, the $[\mathrm{M}]^{+}$becomes the base peak and the $[\mathrm{M}+\mathrm{H}]^{+}$disappears. Because the intensity is not distributed between two peaks any more, the intensity of the $\left[\mathrm{M}^{+}\right]$is increased. The ferrocene unit is oxidized to the ferrocinium cation and protonation of the already charged molecule in the ESI interface is unlikely. Since the oxidation potential of FEM is low enough that some oxidation could already have taken place in the ESI source, the $[\mathrm{M}]^{+}$peak is already present in the mass spectra, which were recorded under regular ESI-MS conditions. That explains why the average charge states and the intensities of the derivatized peptides are increased by LC/EC/MS compared to LC/MS measurements. As already observed for proteins, this increase does not correlate with the number of thiol functionalities and ferrocene labels, respectively. This can be explained by the function of electrospray as an ionization technique. It is likely that additional charges were transferred either by protonation or by electrochemistry in the electrospray needle and not just by electrochemistry before the interface.

An increase in signal intensity was observed for the three signals marked A, B and C in the TIC chromatogram of Fig. 9, due to electrochemical oxidation. Peak B is the excess derivatizing agent. Peak A corresponds to the tryptic peptide LSFNPTQLEEQCHI and peak C to YLLFCMEN SAEPEQSLVCQCLVR (Fig. 10). Only one Cys residue (C 66) was not found in the tryptic digest, either derivatized or underivatized. However, a basic lysine residue is located directly adjacent to the peptide WENDECAQK. It is known from the literature [39] that the likelihood of tryptic cleavage is reduced in this case.

\section{Conclusions}

FEM has proven to be a useful new derivatizing agent for the determination of thiol functionalities by LC/MS, whether or not it is used in conjunction with thiol reduction. Under the optimized conditions employed in this work, the highly selective derivatization of cysteine residues can be achieved, even in the presence of lysine groups. Additional information is obtained by using an electrochemical cell, where the ferrocene units are converted to ferrocinium. An increase in signal after electrochemical treatment indicates the presence of a derivatized cysteine residue in the complete or the tryptically digested peptide. Future work will focus on the simultaneous labelling of free and disulfide-bound thiols using two different ferrocene-based reagents, which can then be distinguished by tandem mass spectrometric measurements.

Acknowledgement Financial support by the Deutsche Forschungsgemeinschaft (Bonn, Germany), the Nederlandse Organisatie voor Wetenschappelijk Onderzoek (NWO, Den Haag, The Netherlands) and the Fonds der Chemischen Industrie (Frankfurt, Germany) is gratefully acknowledged.

\section{References}

1. Jurva U, Wikstrom HV, Bruins AP (2000) Rapid Commun Mass Spectrom 14:529-533

2. Jurva U, Wikstrom HV, Weidolf L, Bruins AP (2003) Rapid Commun Mass Spectrom 17:800-810

3. Permentier HP, Bruins AP (2004) J Am Soc Mass Spectrom 15:1707-1716

4. Van Leeuwen SM, Hayen H, Karst U (2004) Anal Bioanal Chem 378:917-925

5. Hayen H, Karst U (2003) Anal Chem 75:4833-4840

6. Quirke J, Martin E, Van Berkel GJ (2001) J Mass Spectrom 36:179-187

7. Diehl G, Karst U (2002) J Chromatogr A 974:103-109

8. Diehl G, Liesener A, Karst U (2001) Analyst 126:288-290

9. Van Berkel GJ, Quirke JME, Dilley A, Tigani R, Covey TR (1998) Anal Chem 70:1544-1554

10. Diehl G, Karst U (2002) Anal Bioanal Chem 373:390-398

11. Karst U (2004) Angew Chem Int Ed 43:2476-2478

12. Williams D, Chen S, Young MK (2001) Rapid Commun Mass Spectrom 15:182-186

13. Murao N, Ishigai M, Sekiguchi N, Takahashi T, Aso Y (2005) Anal Bioanal Chem 346:158-166

14. Seiwert B, Henneken H, Karst U (2004) J Am Soc Mass Spectrom $15: 1727-1736$

15. Gilbert HF (1998) In: Sinnott M (ed) Comprehensive biological catalysis, vol. 1. Academic, San Diego, CA, pp 609-625

16. Thornton JM (1981) J Mol Biol 151:261-287

17. Luo JL, Hammarqvist F, Cotgreave IA, Lind C, Anderssson K, Wernerman J (1995) J Chromatogr B 670:29 
18. Yen T-Y, Yan H, Macher BA (2002) J Mass Spectrom 37:15-30

19. Shimada K, Oe T, Nambara T (1987) J Chromatogr 419:17-25

20. DiGleria K, Hill HAO (1996) FEBS Lett 390:142-144

21. Salmain M, Jaouen G (2003) C R Chimie 6:249-258

22. Di Gleria K, Darren P, Nickerson H, Allen O, Hill HAO (1998) J Am Chem Soc 120:46-52

23. DiGleria K, Halliwell CM, Jacob C (1997) FEBS Lett 400:155-157

24. Wang Y, Yao X, Wang J, Zhou F (2004) Electroanalysis 16:1755-1761

25. Shimada K, Mitamura K (1994) J Chromatogr B 659:227-241

26. Lednicer D, Lindsay JK, Hauser CR (1958) J Org Chem 23:653-655

27. Katayama Y, Sakakihra S, Madea M (2001) Anal Sci 17:17-19

28. Rosenblum M, Santer JO, Howells WG (1963) J Am Chem Soc $85: 1450-1458$

29. Khan M (1984) J Pharm Sci 73:1767-1771

30. Wetter LR, Deutsch HFr (1951) J Biol Chem 192:237-242
31. Conaway-Jacobs A, Lewin LM (1971) Anal Biochem 43:394-400

32. Bioshop WH, Richards FM (1968) J Mol Biol 33:415-421

33. Jolles $P$ (1969) Angew Chem Int Ed 8:227-239

34. Derewenda U, Dodson GG (1993) In: Diamond R et al (eds) Molecular structures in biology. Oxford University Press, Oxford, pp 260-277

35. Papiz MZ, Sawyer L, Eliopoulos EE, North ACT, Findlay JBC, Sivaprasadarao R, Jones TA, Newcomer ME, Kraulis PJ (1986) Nature 324:383-385

36. Tyagarajan K, Pretzer E, Wiktorowicz JE (2003) Electrophoresis 24(14):2348-2358

37. Burmeister Getz E, Xiao M, Chakrabarty T, Cooke R, Selvin PR (1999) Anal Biochem 273:73-80

38. Han JC, Han GY (1994) Anal Biochem 220:5-10

39. Keil B (1992) Specificity of protolysis. Springer, Berlin, p 335 